\title{
Developmental evaluation: A tool to support innovation
}

\section{Helen McDonald}

The term developmental evaluation was coined by Michael Quinn Patton in the mid-1990s to describe the role of evaluators in the development of an innovative initiative. Core evaluation skills, such as articulating the initiative's theory of change, asking evaluative questions, and providing timely information on emerging results, help the initiative to develop through iterative cycles of learning and adaptation. A growing number of case studies provide valuable insights into the specific situations where developmental evaluation may be useful, the roles and skills required of the evaluator, and the challenges this approach brings. This article provides a concise summary of the insights from theory and case studies to help programme developers and evaluators decide whether and how to use developmental evaluation.

\section{Introduction}

There is significant demand across the world and across the public, private, and non-profit sectors for innovation (Patton, 2016a). Developmental evaluation supports the creation of innovative initiatives to address complex problems. In developmental evaluation 
the evaluator collaborates closely with the development team. The evaluator uses skills such as asking evaluative questions, applying programme logics, and data collection and analysis to inform the development process. Developmental evaluation's purpose is therefore quite distinct from the purpose of more traditional formative and summative evaluations. While formative and summative approaches are focused on improving or assessing an established initiative, developmental evaluation aims to generate timely learning to assist development before there is a complete model to improve or assess (Dozois, Langlois \& Blanchet-Cohen, 2010). The primary users of a developmental evaluation are the individuals and organisations seeking to achieve significant change (Patton, 2011). The success of the evaluation is measured by the extent to which the knowledge and lines of inquiry it helps produce contribute to the development process (Lam, 2012).

Developmental evaluation is still a relatively new approach. Wehipeihana and McKegg (as cited in Patton, 2011) have previously observed that it is not well understood in New Zealand. First articulated by Patton in 1992, it has been further developed by contributions from Gamble (2008), Dozois et al. (2010), Patton (2011), and Preskill and Beer (2012). Knowledge about when and how to use it is gradually being built up through the publication of a number of case studies discussing its use in New Zealand and overseas. These examples provide valuable insights into the types of projects where developmental evaluation may be useful, the roles the evaluator may play, and the impact of developmental evaluation.

The purpose of this article is to provide a concise introduction to the theory and the practice of developmental evaluation to assist New Zealand programme developers and evaluators to determine whether and how to use it. It looks at the specific situations where developmental evaluation is of value, what an evaluator contributes to the 
development process, the skills and qualities required for developmental evaluation, and the challenges that arise.

\section{Situations suitable for developmental evaluation}

Developmental evaluation is promoted as a tool to aid the ongoing development and adaptation of innovative initiatives in complex situations (Patton, 2011). Key characteristics of complex situations include:

- unpredictability-variables are non-linear, with small actions potentially having large effects (Walton, 2014)

- high levels of uncertainty, with no known solutions and no clear way forward (Dozois et al., 2010)

- rapid and unpredictable change (Patton, 2011)

- outcomes emerging as elements of the system adapt and evolve in response to changing circumstances (Patton, 2011)

- the need for collaboration between stakeholders, given many interdependent variables (Patton, 2016a).

Innovative initiatives in this context are likely to be driven by vison and values rather than a clear intended outcome, and they require collaboration between multiple stakeholders (McKegg \& Patton, 2014, as cited in McKegg, 2015). Dickson \& Saunders (2014) note that developmental evaluation is used in situations where the implementation approach is more akin to "ready, fire, aim", rather than the more traditional approach of "ready, aim, fire" (p. 178).

Patton (2011) identified five specific complex situations, likely to overlap, as the niche for developmental evaluation:

- when ongoing development is needed to adapt an initiative to changing conditions (for example, in technology or demographics) in a complex, dynamic environment 
- when initiatives that have been effective in one setting are adapted to a new environment

- when there is a need to quickly respond to a crisis or sudden significant change, such as a natural disaster

- during the early development of an innovation that has the scope to be applied more broadly

- during substantial systems change.

Two case studies considered in this article primarily concern the development needed to adapt an initiative to a new environment. The other case studies discussed here use developmental evaluation to assist the early development of an innovation.

\section{What an evaluator brings to the development process}

When developing initiatives in highly uncertain, emergent situations, the skills of an evaluator help remove some of the uncertainty that can be a barrier to innovation. These skills include:

- helping to articulate the objectives and success measures of the initiative

- providing data as initial impacts emerge

- recording the lessons learned

- building stakeholders' capacity to use data to manage the initiative.

Helping to articulate the objectives and success measures of the initiative

One of the core roles for a developmental evaluator is to ask evaluative questions to prompt discussion and help the project team progress its thinking (Patton, 2011). These might be focused on several areas: drawing out the nature of the problem; clarifying which aspects of the initiative need to adapt; the underlying values and assumptions; and the criteria for success (Lam, 2012). The Māori and Pacific 
Educational Initiative (MPEI) involved multiple different initiatives over a 5-year period, in different communities, with different needs. As part of the development team, the evaluators worked to develop key success criteria with the trustees of the philanthropic trust who were funding the initiative. These criteria were used to provide a framework to help develop the detail of the initiative beyond its highlevel vision of improving Māori and Pacific educational achievement (McKegg, Wehipeihana, Becroft \& Gill, 2016). Lam (2012) noted that in developing the Assessment Pilot Initiative (API), an innovative approach to teacher education using Twitter at a Canadian university, the development team and the evaluator collaboratively used evaluative questioning to judge how well particular ideas fitted or could be adapted to the proposed initiative.

Patton (2011) notes that the deep knowledge accumulated by an experienced evaluator about the nature of what is likely to work is very useful in helping a development team articulate an initiative's programme theory. Programme theory was used to provide a framework to inform the development of the Assessment Pilot Initiative (Lam \& Shulha, 2015). In New Zealand, McKegg, Wehipeihana, Pipi and Thompson (2013) used a developmental evaluation approach to support the implementation of a significant change in focus for $\mathrm{He}$ Oranga Poutama. In 2009 the objectives of this Sport New Zealand initiative changed from increasing the participation "by Māori” in sport to participating and leading "as Māori" in sport. Wehipeihana and McKegg (2009) consider that a developmental evaluation approach was appropriate as there was little experience of how to apply the concept of as Mãori, and the change in focus was based on a vision rather than clear, measurable goals. Further, they note that diverse organisations were involved in its implementation in a complex environment. This environment included a deteriorating economy and ongoing changes in Sport New Zealand. Developmental 
evaluation facilitated the development of a shared understanding of the concept of as Máori in sport, and the development of a framework-Te Whetu Rēhua-which formed the basis for assessing the fit of a range of programmes with the initiative (Wehipeihana, McKegg, Thompson, \& Pipi, 2016).

\section{Providing data as initial impacts emerge}

In a developmental evaluation data gathering and reporting is required in real time to inform decisions in an ongoing and timely way (McKegg et al., 2016). Such decisions include where future attention should be focused or how the initiative should be altered (Patton, 2011; Preskill \& Beer, 2012). This contrasts with traditional evaluations where data collection and reporting may follow a linear, planned process. During the developmental evaluation of the Māori and Pacific Educational Initiative, the evaluators found that instead of an approach of interim and final reports, the needs of the trustees of the philanthropic trust to be kept informed of progress were better met by regular, shorter reports containing quantitative data as it became available (McKegg et al., 2016).

Lam and Shulha (2015) consider that the nature of the data used in the development of a teacher education tool was broader than what is traditionally collected in a summative evaluation, such as data about an initiative's activities or outcomes. For example, the data provided included information from the social science and education literature about the use of technology to assist learning, which provided the development team with new ideas for the initiative.

The case studies highlight the impact of data collected during the development of the initiative. For example, Lam (2012) notes that the information gathered on the piloting of Twitter with a group of student teachers highlighted the limitations of learning through a short tweet. The development team was able to respond by including 
a discussion board alongside Twitter. Fagen et al. (2011) discuss the use of data in the developmental evaluation of the Illinois Caucus for Adolescent Heath initiative to change school board sexual-education policies. They note that information gathered through surveys, focus groups, and interviews confirmed an initial view that the presence of a core group advocating for change was a critical factor in achieving change in a school district's policy.

\section{Recording the lessons learned}

A key role of the developmental evaluator is in recording what the development is seeking to achieve, what decisions are taken and why, what emerges, and what was learned (Patton, 2008). Lam (2012) notes that the developers of the Assessment Pilot Initiative observed that, given the fast changing nature of the development, the summaries he produced of the development discussions and steps taken along the way were very useful for helping them to understand and keep track of where the development was at. Documenting the process also makes the process more transparent, supports accountability, and provides a valuable resource for future interventions (Gamble, 2008).

\section{Building stakeholders' capacity to use data to manage the initiative}

The close involvement of the evaluator in a developmental evaluation can build stakeholders' knowledge of evaluation and their capacity and inclination to gather and use data to inform their practice. McKegg et al. (2013) note that an important part of the evaluators' role was to work with the providers to co-construct a monitoring framework for He Oranga Poutama. The objective was to provide an evidence base so that providers and Sport New Zealand could know the type and number of as Mãori activities being funded. This monitoring framework was subject to ongoing testing and refining. While the extent to which the providers understood evaluation at the end 
of the programme varied, they all reported learning something about the key aspects of evaluation (McKegg et al., 2013).

\section{The skills and qualities required for developmental evaluation}

To work collaboratively in the development process requires the evaluator to possess a broad range of skills and qualities. The following section discusses four key qualities:

- the ability to build trusting relationships

- cultural fit and competence

- strong methodological skills

- an in-depth understanding of the initiative.

\section{The ability to build trusting relationships}

Given the collaborative learning essential for a developmental evaluation process, fundamental abilities are: to build strong, trusting relationships with management, staff, and stakeholders; to actively listen; and to facilitate participation (Langlois, Blanchet-Cohen \& Beer, 2013; McKegg \& Patton, 2014, as cited in McKegg, 2015). The evaluators also need to understand when, and how, to provide feedback in a way that will support development (Langlois et al., 2013).

The strong relationship focus of developmental evaluation lends itself very well to development taking place in a Māori context. McKegg et al. (2013) note that in a Māori community evaluation has more credibility if the evaluator is known to the community and is perceived as understanding the community and its priorities. They consider that their role was made easier by their pre-existing relationships with the manager of the He Oranga Poutama programme and some providers. 


\section{Cultural fit and competence}

An important influence on the ability of the evaluators to effectively support the development of an initiative is the cultural fit between the values, characteristics, and language of the culture(s) developing the initiative and the evaluator (Goodwin, Sauni \& Were, 2015). In the New Zealand case studies considered here, Māori and Pasifika evaluators were part of the evaluation teams. In the evaluation to support the development of Whānau Ora for Youth Mental Health services by Māori and Pasifika service providers, Goodwin et al. (2015) observe that, particularly at the beginning of the evaluation, the cultural fit of the evaluation team-consisting of one Pasifika and two Māori evaluators_-was important to the service providers. With the implementation of as Mãori in sport, the evaluators of $\mathrm{He}$ Oranga Poutama deliberately placed Māori values, cultural concepts, and te reo Māori at the heart of their evaluation approach (McKegg et al., 2016). The evaluators chose methods to accurately and appropriately capture the views and experiences of Māori providers and communities (McKegg et al., 2013). This included regular hui and facilitation methods that included waiata (songs) and mahi toi (arts and crafts) that would encourage everyone to share their experiences. They noted that providers said they appreciated the emphasis that the evaluators placed on face-to-face sharing and learning from one another (McKegg et al., 2013).

Cultural competence is recognised as encompassing more than an evaluation carried out in a culturally appropriate way, to also encompass "drawing on the values, needs, strengths and aspirations of the culture of those a policy or programme is intended to benefit" to determine what successful design, delivery, and outcomes for the initiative look like (Aotearoa New Zealand Evaluation Association, 2011, p.10). As already noted, McKegg et al. (2013) drew on Māori values and perspectives to develop a shared understanding of the 
concept of as Mãori in sport and the outcome framework, Te Whetu Rēhua (Wehipeihana et al. 2016). In the development of Whānau Ora for Youth Mental Health services, discussions with the Pasifika and Māori service providers highlighted the importance of cultural fit to the initiative and this was incorporated in the success criteria that the evaluators developed with each of the providers.

\section{Strong methodological skills}

Given the range of functions an evaluator may need to carry out, it is valuable for developmental evaluators to have strong methodological skills and experience with a wide range of methods (Wehipeihana $\&$ McKegg, 2009). These include strong analytical and data-analysis skills, and the ability to think strategically and see the big picture (Dozois et al., 2010). Patton (2016b) also observes that knowledge of systems and complexity theory is important for a developmental evaluator in understanding the nature of the innovative initiative, how it might emerge, and the impact of interactions with other parts of the system.

The evaluator must also be flexible and able to adapt their methods and areas of focus in response to emerging issues (Patton, 2011). Thus Fagen et al. (2011) noted that in the initiative to change school board sexual-education policies in Illinois, the evaluation team revised its logic model at the beginning of Phase 2 using its findings from Phase 1. The team also revised its evaluation questions and methods.

\section{An in-depth understanding of the initiative}

Alongside these skills is the need for the evaluators to have an in-depth understanding of the initiative (Wehipeihana, 2015). This includes understanding the issues to be addressed, key stakeholders, the wider system, and the resources available (time and financial) (Dozois et al., 2010). Going a step further, specific subject knowledge can also be a significant advantage (Dozois et al., 2010). Lam (2012) observes that 
his knowledge of teacher education and communication technologies such as Twitter was one of the reasons the developers selected him, and he was able to significantly shape the development in a manner that would not have been not possible without that knowledge.

Most case studies considered here used a team of evaluators, providing a broader knowledge and skill set and the ability to support each other. Honadle, Zapata, Auffrey, vom Hofe and Looye (2014) consider that a real strength was derived from the multidisciplinary nature of the evaluation team involved in the Stronger Economies Together initiative. The depth of relevant knowledge and credibility it provided enabled the evaluation team to have a substantive input into the initiative.

\section{The challenges of developmental evaluation}

While developmental evaluation seems like a common-sense approach involving an ongoing cycle of learning and adapting, it is challenging in practice and will not be the right tool for every complex situation. Some of the challenges faced by developmental evaluators include:

- achieving buy-in

- defining the boundaries of the evaluator's role

- balancing the need for in-depth knowledge and objectivity

- providing robust data in real-time.

\section{Achieving buy-in}

A crucial factor for a successful developmental evaluation is that key stakeholders understand and demonstrably buy-into the developmental evaluation approach (Patton, 2011). They must be open to experimentation, reflection, and using evaluative data to adapt the initiative as needed (Preskill \& Beer, 2012). A lack of understanding of evaluation in general, and of developmental evaluation in particular, reduces the likelihood of buy-in to developmental evaluation 
(Poth, Pinto \& Howery, 2012). McKegg and Wehipeihana (2015) note that they often find it necessary to explain the purpose and process of evaluation before going on to explain developmental evaluation. Ramirez, Shephard and Kora (2015) described their use of developmental evaluation in the continuing development of a social and financial education programme aimed at youth. On-site face-toface engagement with the programme funder and the client facilitated getting buy-in to the approach. The funder's key priority was that the evaluation produced useful knowledge for the programme. This provided the development team with the freedom needed to explore a range of potential opportunities. Similarly, buy-in is impeded by the concern that developmental evaluation will not provide the evidence of the value of the initiative that is sought (McKegg \& Wehipeihana, 2016). Regular reports about the project's progress and what has been learnt can help to address this (Poth et al., 2012). This issue can also be addressed through the development of trusting relationships, along with the credibility built up from a track record of previous successful evaluation work (Wehipeihana \& McKegg, 2009).

\section{Defining the boundaries of the evaluator's role}

Developmental evaluation is not prescriptive in the manner in which it is approached and applied. The design and methods depend on the nature of the situation and the key questions that need to be answered to progress its development (Dozois et al., 2010; Patton, 2011). One challenge arising from this flexibility is the need to clearly define roles and responsibilities to ensure all parties are clear what will be undertaken by the evaluators and the time and resources that will be needed (Wehipeihana, 2015). Poth et al. (2012) discuss the developmental evaluation undertaken to support the development and implementation of an educational technology leadership project funded by the Alberta provincial government. They note that it was 
challenging to define the boundary between the evaluation and project activities. Because the responsibilities of the evaluator increased over time it was agreed that the evaluation team would only deal with tasks that would inform project development.

\section{Balancing the need for in-depth knowledge and objectivity}

The degree of power and control a development team is willing to give the evaluator will vary and this affects the extent to which the evaluator can influence the development (Lam \& Shulha, 2015). A developmental evaluator often has to strike a balance between the detailed understanding and opportunities for influence that come with being part of the team and being independent and objective (Gamble, 2008). Dozois et al. (2010) note that an internal staff member working as a developmental evaluator has existing relationships and knowledge. However, they may be seen as less objective, may struggle to keep their role clearly defined, and they may find it difficult to provide frank feedback. External developmental evaluators may be more objective, may have insights from previous projects from which to draw insights, and may be clearer on their role. However they have less direct knowledge, they need to invest time to establish relationships, and they may have less time due to cost (Dozois et al., 2010).

\section{Providing robust data in real-time}

Some case studies note the challenges of data collection in a fast-moving development, where issues emerge quickly and the desire for real-time feedback makes collecting reliable data difficult. Collecting data on He Oranga Poutama was challenging given the variety of different contexts and activities through which it was delivered and the logistics of collecting individual and group data (McKegg et al., 2013). In this instance, the quality of the data collected improved in the second year as providers and Sport New Zealand became 
more experienced in their respective roles of collecting and analysing the data. Data collection was assisted by basing the monitoring framework on Te Whetu Rēhua, the framework for implementing the concept of as Mãori in sport. Because the framework was based on Māori cultural knowledge and practice, and developed with the involvement of the providers, data collection was made more real and important to providers. Data collection was also facilitated by $\mathrm{He}$ Oranga Poutama reporting back on results at national and regional levels. This enabled the providers to see that the data was useful both to Sport New Zealand and to their own organisations. In the evaluation of an educational technology leadership programme, Poth et al. (2012) note that the evaluators were responsible for ensuring data was available on an ongoing basis to inform decisions. However, they found that administrators only posted about their technology experiences when they were successful, in part because they were uncertain of how this information would be used in the development of the initiative. To address this, questions were used to guide online feedback and on the evaluation team's suggestion, their client demonstrated the type of information that was sought.

\section{Conclusion}

Complex situations often have no clear way forward, with outcomes emerging as the elements of the system adapt and evolve in response to changing circumstances in a non-linear fashion. Developmental evaluation provides a potential tool for reducing the high level of uncertainty. This is achieved by core evaluation skills, such as asking evaluative questions and using data collection and analysis. These skills help to articulate the objectives and success measures of an initiative, and provide data on initial impacts as they emerge. The recording of the process and the lessons learnt provides a valuable resource for future developments. The close involvement of the 
evaluator can build stakeholders' knowledge of evaluation and their capacity and inclination to gather and use data to inform their practice. Further, the use of developmental evaluation in New Zealand shows that the strong relationship-based focus of this approach lends itself well to development taking place in Māori and Pasifika contexts.

However, developmental evaluation is not the right tool for every complex situation. Before proceeding with a developmental evaluation approach, the project commissioners, design team, and potential evaluator should carefully consider the extent to which they are able to respond positively to a number of key questions, which include the following.

- Do the project commissioners and development team understand the developmental evaluation approach?

- Are the project commissioners and development team open to an iterative development process, using evaluative data to learn and adapt the initiative as needed?

- Have the key parties established, or are confident they are able to establish, a strong, trusting relationship?

- Is the evaluator comfortable with providing data in real-time and willing to change evaluation methods in response to emerging issues?

- Does the evaluator have a deep understanding of the issues to be addressed, the interests of key stakeholders, and how the different elements of the system interact?

- Have the parties considered the extent to which subject-specific knowledge is required?

- Have the roles and responsibilities of the developmental evaluator been considered and agreed? 
The insights provided by the theoretical literature and the case studies considered in this article show that when project commissioners, developers, and evaluators are willing and able to commit to the use of evaluative skills to support the development process, developmental evaluation can help reduce the uncertainty inherent in developing initiatives to address complex situations. The case studies considered here identify the benefits and challenges of developmental evaluation primarily from the perspective of the evaluator. While some of the case studies touch on the feedback they received from providers, the perspectives of the clients of developmental evaluation - the funders and developers of innovative initiatives-would be an interesting area for further research.

\section{References}

Aotearoa New Zealand Evaluation Association. (2011). Evaluator competencies. Retrieved from http://www.anzea.org.nz/wp-content/ uploads/2013/05/110801_anzea_evaluator_competencies_final.pdf.

Dickson, R. \& Saunders, M. (2014). Developmental evaluation: Lessons for evaluative practice from the SEARCH program. Evaluation, 20(2), 176-194. http://dx.doi.org/10.1177/1356389014527530

Dozois, E., Langlois, M., \& Blanchet-Cohen, N. (2010). DE 201: A practitioner's guide to developmental evaluation. Retrieved from http://www.mcconnellfoundation.ca/assets/Media\%20Library/ Publications/DE\%2 0201\%20EN.pdf.

Fagen, M. C., Redman, S. D., Stacks, J., Barrett, V., Thullen, B., Altenor, S. \& Neiger, B. L. (2011). Developmental evaluation: Building innovations in complex environments. Health Promotion Practice, 12(5), 645-650. http://dx.doi.org/10.1177/1524839911412596

Gamble, J. A. (2008). A developmental evaluation primer. Montreal: JW McConnell Family Foundation.

Goodwin, D., Sauni, P. \& Were, L. (2015). Cultural fit: An important 
criterion for effective interventions and evaluation work. Evaluation Matters-He Take Tō Te Aromatawai, 1, 25-46.

http://dx.doi.org/10.18296/em.0003

Honadle, B. W., Zapata, M. A., Auffrey, C., vom Hofe, R. \& Looye, J. (2014). Developmental evaluation and the 'Stronger Economies Together' initiative in the United States. Evaluation and Program Planning, 43, 64-72. http://dx.doi.org/10.1016/j.evalprogplan.2013.11.004

Lam, C. Y. (2012). A case study on the use of developmental evaluation for innovating: navigating uncertainty and unpacking complexity. (Master's Thesis, Queen's University, Ontario, Canada). Retrieved from http://hdl.handle.net/1974/6935.

Lam, C. Y. \& Shulha, L. M. (2015). Insights on using developmental evaluation for innovating: A case study on the co-creation of an innovative program. American Journal of Evaluation, 36(3) 358-374. http://dx.doi.org/10.1177/1098214014542100

Langlois, M., Blanchet-Cohen, N., \& Beer, T. (2013). The art of the nudge: Five practices for developmental evaluators. The Canadian Journal of Program Evaluation, 27(2), 39-59.

McKegg, K. (2015, 2 March). Developmental Eval Week: Kate McKegg on Readiness for Developmental Evaluation [Online forum comment]. Retrieved from http://aea365.org/blog/developmental-eval-week-katemckegg-on-readiness-for-developmental-evaluation/.

McKegg, K. \& Wehipeihana, N. (2015, 14 April). Developmental evaluation week: Kate McKegg and Nan Wehipeihana on talking to clients and communities about developmental evaluation [Online forum comment]. Retrieved from http://aea365.org/blog/de-week-kate-mckeggand-nan-wehipeihana-on-talking-to-clients-and-communities-aboutdevelopmental-evaluation/.

McKegg, K. \& Wehipeihana, N. (2016). Developmental evaluation in synthesis. Practitioners' perspectives. In M. Q. Patton, K. McKegg \& N. Wehipeihana (Eds.), Developmental evaluation exemplars: Principles in practice (pp. 271-288). New York, NY: Guildford Press. 
McKegg, K. \& Wehipeihana, N., Pipi, K. \& Thompson, V. (2013). He Oranga Poutama: What we have learned. A report on the developmental evaluation of He Oranga Poutama. Wellington, Sport New Zealand.

McKegg, K., Wehipeihana, N., Becroft, M., \& Gill, J. (2016).

Developmental evaluation's role in supporting community-led solutions for Māori and Pacific young people's educational success: The Foundation North Māori and Pacific Education Initiative. In M. Q. Patton, K. McKegg \& N. Wehipeihana (Eds.), Developmental evaluation exemplars: Principles in practice (pp. 125-142). New York, NY: Guildford Press.

Patton, M. Q. (1992). Developmental evaluation: An approach for empowerment-oriented and multi-cultural programs. New Directions for Program Evaluation, 53, 17-33.

Patton, M. Q. (2008). Utilization-focused evaluation ( $4^{\text {th }}$ ed). Thousand Oaks, CA: Sage.

Patton, M. Q. (2011). Developmental evaluation: Applying complexity concepts to enhance innovation and use. New York, NY: The Guilford Press.

Patton, M. Q. (2016a). State of the art and practice of developmental evaluation: Answers to common and recurring questions. In M. Q. Patton, K. McKegg \& N. Wehipeihana (Eds.), Developmental evaluation exemplars: Principles in practice (pp. 1-24). New York, NY: Guildford Press.

Patton, M. Q. (2016b). The developmental evaluation mindset: Some guiding principles. In M. Q. Patton, K. McKegg \& N. Wehipeihana (Eds.), Developmental evaluation exemplars: Principles in practice (pp. 289-312). New York, NY: Guildford Press.

Poth, C., Pinto, D. \& Howery, K. (2012). Addressing the challenges encountered during a developmental evaluation: Implications for evaluation practice. The Canadian Journal of Program Evaluation, 26(1), 39-48.

Preskill, H. \& Beer, T. (2012). Evaluating social innovation. Retrieved from http://guelph.ca/wp-content/uploads/contract_12-191_description.pdf.

Ramírez, R., Shephard, D. \& Kora, G. (2015). Utilization focused developmental evaluation: Learning through practice. Journal of 
MultiDisciplinary Evaluation, 11(24), 37-53.

Walton, M. (2014). Applying complexity theory: A review to inform evaluation design. Evaluation and Program Planning, 45, 119-126. http://dx.doi.org/10.1016/j.evalprogplan.2014.04.002

Wehipeihana, N. \& McKegg, K. (2009, November 14). Developmental evaluation in an indigenous context: Reflections on the journey to date. Paper presented at the American Evaluation Association Conference, Orlando, FL. Wehipeihana, N. (2015, March 03). Developmental eval week: Nan Wehipeihana on roles and responsibilities in developmental evaluation [Online forum comment]. Retrieved from http://aea365.org/blog/ developmental-eval-week-nan-wehipeihana-on-roles-and-responsibilitiesin-developmental-evaluation/?utm_source=feedburner\&utm_ medium=email\&utm_campaign=Feed\%3A+aea365+\%28AEA365\%29

Wehipeihana, N., McKegg, K., Thompson, V. \& Pipi, K. (2016). Cultural responsiveness through developmental evaluation: Indigenous innovations in sport and traditional Māori recreation. In M. Q. Patton, K. McKegg \& N. Wehipeihana (Eds.), Developmental evaluation exemplars: Principles in practice (pp. 25-44). New York, NY: Guildford Press.

\section{The author}

Helen McDonald is a senior analyst at the New Zealand Treasury, and a member of its Regulatory Quality Team. The views expressed in this article are nonetheless those of the author and do not necessarily reflect the views of the New Zealand Treasury. Helen is also currently enrolled in the Postgraduate Diploma in Social Sector Evaluation Research at Massey University. Email: hmcdonald18@gmail.com 